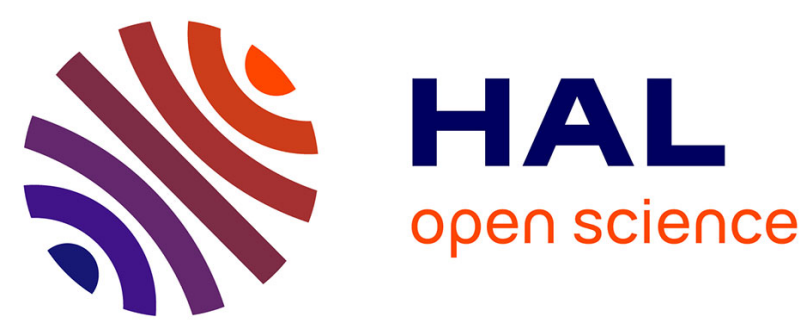

\title{
Electric Field Distribution in HVDC Cable Joint in Non-Stationary Conditions
}

\author{
G. Teyssedre, Thi Thu Nga Vu, Séverine Le Roy
}

\section{To cite this version:}

G. Teyssedre, Thi Thu Nga Vu, Séverine Le Roy. Electric Field Distribution in HVDC Cable Joint in Non-Stationary Conditions. 13th International Conference on the Properties and Applications of Dielectric Materials (ICPADM 2021), Jul 2021, Johor Bahru (virtuel), Malaysia. pp.406-409, 10.1109/ICPADM49635.2021.9493863 . hal-03326472

HAL Id: hal-03326472

https://hal.science/hal-03326472

Submitted on 26 Aug 2021

HAL is a multi-disciplinary open access archive for the deposit and dissemination of scientific research documents, whether they are published or not. The documents may come from teaching and research institutions in France or abroad, or from public or private research centers.
L'archive ouverte pluridisciplinaire HAL, est destinée au dépôt et à la diffusion de documents scientifiques de niveau recherche, publiés ou non, émanant des établissements d'enseignement et de recherche français ou étrangers, des laboratoires publics ou privés. 


\title{
Electric Field Distribution in HVDC Cable Joint in Non-Stationary Conditions
}

\author{
Gilbert Teyssedre $^{1^{*}}$, Thi Thu Nga Vu ${ }^{2}$, Séverine Le Roy ${ }^{1}$ \\ ${ }^{1}$ Laplace, University of Toulouse and CNRS, Toulouse, France \\ ${ }^{2}$ Electric Power University, Hanoi, Vietnam \\ *gilbert.teyssedre@laplace.univ-tlse.fr
}

\begin{abstract}
Accessories such as joints and terminations represent a weak point in HVDC cable systems. Indeed, the DC field distribution is intimately dependent on the thermal condition of the accessory and on material properties. Moreover, there is no available method to probe charge distribution in those conditions. In this work, the field distribution in non-stationary conditions, both thermally and electrically, is computed considering different insulating materials assembled in a same geometry, with focus on the tangential field distribution. We show that the position of the maximum field varies in time in a way that is not easy to anticipate. The work points to the need of precise data on materials conductivity and to the need to probe field distribution in 3D.
\end{abstract}

Keywords-HVDC cable joints, field distribution, FEM simulation, XLPE

\section{INTRODUCTION}

Accessories may represent a weak point in HVDC cable links, especially when going to ever-higher voltages where feedback on in-service behaviour is lacking. Compared to bulk cables where many research works are carried out, both experimentally and in modelling, for assessing insulation endurance, anticipating field distribution in accessories is more difficult to tackle. Especially, methods for probing charge and field distribution on localized areas are lacking and the fact that different insulating materials coexist brings further difficulty. For this reason, thermal and electrical modelling is necessary. Resorting to macroscopic modelling, i.e. based on field and temperature dependencies of conductivity and/or permittivity, the numerical resolution of the problem is not a real difficulty. However, it must be based on reliable experimental data characterizing the materials, especially conductivity, and also on the exploration of different practical combinations of thermal/electrical stresses that may be encountered.

Whereas the behaviour of the radial field distribution in a bilayer dielectric can be reasonably anticipated based on the conductivity behaviour, the tangential component is more difficult to tackle, especially the respective role of geometry and thermal stress. It is recognized that the dielectric/dielectric interface represents a threat for the accessory reliability and the tangential field can be a driving mode for failure [1-4].

In this work, based on a conductivity law established from experiments on typical materials that are XLPE (crosslinked polyethylene), SiR (silicone rubber), and EPDM (ethylenepropylene diene monomer) copolymer, we compute the field distribution in a $200 \mathrm{kV}$ cable joint. We consider polarity reversal of the DC stress and different thermal conditions: isothermal at $30^{\circ} \mathrm{C}$ and non-stationary thermal gradient when energizing the cable. The tangential and radial electric fields are computed in these transient electrical and thermal conditions. To evaluate how far the nature of material imparts the field distribution, we consider the case of a joint fully made with XLPE, as could be the case for factory joints Erreur ! Source du renvoi introuvable.], and silicone rubber ( $\mathrm{SiR})$ associated to XLPE.

\section{JOINT CHARACTERISTICS AND MODEL}

\section{A. Geometry}

The object of the present study is a $200 \mathrm{kV}, 1 \mathrm{kA}$ HVDC joint with general design and geometry as given in Fig. 1 [5]. It is made of a copper conductor, cable insulation (XLPE), joint material (EPDM) and various layers of semiconductor material (carbon black charged polymer). Field distribution cones are present at both ends of the junction. In the model described here, the outer layer is simplified by using a $5 \mathrm{~mm}$ thick semiconductor layer ensuring electrical continuity and providing thermal resistance at the surface of the joint.

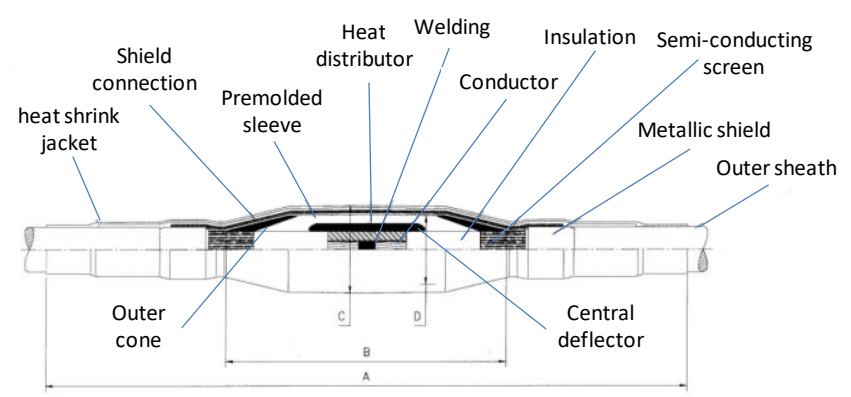

Fig. 1. Scheme of the modelled joint with main approximate dimensions: length $800 \mathrm{~mm}$, conductor diameter $8 \mathrm{~mm}$, insulation thickness $20 \mathrm{~mm}$ in the cable and $70 \mathrm{~mm}$ in the joint.

\section{B. Modelling conditions}

The data on conductivity versus field and temperature of XLPE and EPDM materials are detailed elsewhere [6], [7]. The following equation has been parameterized using experimental current data obtained on plane samples.

$$
\sigma(T, E)=A \cdot \exp \left(\frac{-E_{a}}{k_{B} T}\right) \cdot \sinh (\beta(T) \cdot E) \cdot E^{\alpha}
$$

where the pre-exponential factor $A$, activation energy $E_{a}$, field coefficients $\beta$ and $\alpha$ are given in [7] and $\mathrm{k}_{\mathrm{B}}$ is the Boltzmann's constant. For the silicone rubber, we used the expression of conductivity given by Baferani et al [8]:

$$
\sigma(T, E)=A \cdot \exp (\gamma T) \cdot \exp (\beta E)
$$

with $\mathrm{A}=2.9 \times 10^{-17} \mathrm{~S} / \mathrm{m}$, temperature coefficient $\gamma=0.019 \mathrm{~K}^{-}$ ${ }^{1}$ and $\beta=4.1 \times 10^{-16} \mathrm{~mm} / \mathrm{kV}$. Fig. 2 shows a comparison of conductivity as a function of the field for the different 


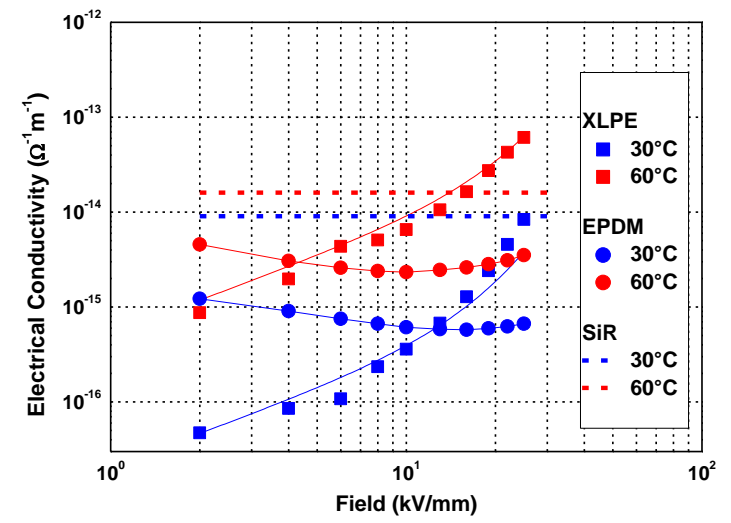

Fig. 2. Field dependence of the electrical conductivity of XLPE, EPDM and $\mathrm{SiR}$ at 30 and $60^{\circ} \mathrm{C}$.

materials at different temperatures. Comparing XLPE and EPDM, the conductivity is sometimes higher in one material or the other, depending on the field and temperature conditions, which will result in a transfer of the DC field in one or the other of the materials according to these same conditions. The conductivity of SiR exhibits very weak field dependence and relatively mildly temperature dependence.

The other physical quantities used in the model are reported in Table I. The heat input by the Joule effect in the copper conductor takes into account a reference resistivity of $1.7 \times 10^{-8} \Omega . \mathrm{m}$ for copper at $20{ }^{\circ} \mathrm{C}$ and a temperature coefficient for the resistivity of $3.9 \times 10^{-3} \mathrm{~K}^{-1}$.

TABLE I.

MATERIAL PARAMETERS USED IN THE MODEL.

\begin{tabular}{lllll}
\hline & XLPE & EPDM & SiR & Semicon \\
\hline Relative permittivity $\varepsilon_{\mathrm{r}}$ & 2.3 & 2.9 & 3.5 & 2.3 \\
Thermal cond. $\lambda(\mathrm{W} / \mathrm{m} / \mathrm{K})$ & 0.38 & 0.30 & 0.20 & 0.34 \\
Specific heat $c_{\mathrm{p}}(\mathrm{J} / \mathrm{g} / \mathrm{K})$ & 1.90 & 0.73 & 2.25 & 1.9 \\
Electrical cond. $\sigma(\mathrm{S} / \mathrm{m})$ & & cf. $[7]$ & cf. $(2)$ & $6.0 \times 10^{3}$ \\
\hline
\end{tabular}

The field and temperature distributions have been resolved using Comsol Multiphysics software, with applying a DC voltage of $+/-200 \mathrm{kV}$ to the conductor and considering either isothermal conditions or thermal gradient induced by injecting a current of $1 \mathrm{kA}$ in the conductor. Switching from positive to negative polarity is done after $24 \mathrm{~h}$ with an intermediate shortcircuit of $3 \mathrm{~min}$.

Thermal modelling considers a heat input by Joule effect in the conductor of $50 \mathrm{~mm}^{2}$ cross section. Heat exchange with the surrounding environment is assumed to occur by natural convection, using a convective transfer coefficient of $\approx 5 \mathrm{~W} /$ $\mathrm{m}^{2} / \mathrm{K}$ taking into account the geometry of the cable. It is rigorously determined in the resolution software. The heat flux exchanged by radiation is also taken into account by considering a surface emissivity coefficient of 0.8 .

\section{RESUlts AND DiscuSSION}

\section{A. Radial electric field}

Results obtained for the radial distribution of the field at a position at half way between the outer cone and central deflector are shown in Fig. 3 for XLPE/EPDM joint. The axial component of the field is almost zero at this position (cf. $\S$ III.B). The field distribution under isothermal conditions (Fig. 3a) is clearly different from the one under thermal gradient (Fig. 3b). At 100s, the field is capacitively distributed (E $\mathrm{E}_{\mathrm{XLPE}}>$ $\left.\mathrm{E}_{\mathrm{EPDM}}\right)$. It gradually evolves in time with further field reinforcement in XLPE, without any pronounced change in the general shape. This evolution corresponds to two phenomena: on the one hand it is the consequence of a resistivity higher in XLPE than in EPDM, at $30^{\circ} \mathrm{C}$, for fields $<10 \mathrm{kV} / \mathrm{mm}$, cf. Fig. 2. The other aspect is that the fields stay moderate so that the nonlinear phenomena, tending to a homogenization of the field over time, are barely perceptible in the two materials.

Under the conditions of a thermal gradient, the electric field rapidly evolves towards a situation of equilibrium; we can consider that after 8 hours the steady state is nearly reached, cf. Fig. 3b. Here for each of the materials the field tends to increase with the radius: this is due to the fact that the thermal gradient produces a conductivity gradient whose effects exceed the variation of the field due to the cylindrical geometry. The residual field, taken $100 \mathrm{~s}$ after resetting the potential to zero, presents a profile substantially different from that of the isothermal case. The lower value of the residual field near the XLPE/EPDM interface results from the fact that with a temperature at the dielectric / dielectric interface of 45 ${ }^{\circ} \mathrm{C}$, and fields of the order of $3 \mathrm{kV} / \mathrm{mm}$, the conductivities of the two materials are quite close. Except for the field step at the interface, the field profile is not very different from the one obtained in the case of XLPE/XLPE joint (Fig. 4a). In addition, by comparing the on and off field jump, it can be seen that it decreased within $100 \mathrm{~s}$ after resetting the potential, due to the partial dissipation of the interface charge. When the polarity is reversed, the field at the core is strongly reinforced.

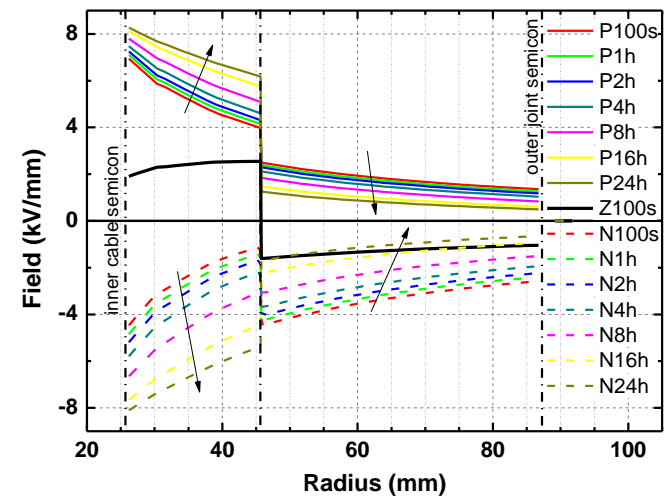

a) XLPE/EPDM Isotherm $30^{\circ} \mathrm{C}$

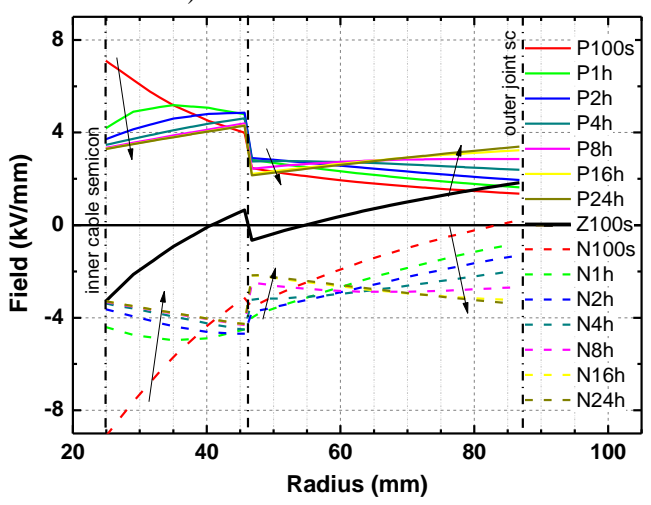

b) XLPE/EPDM T-gradient

Fig. 3. Radial field distribution in the joint (taken at $z \approx 220 \mathrm{~mm}$, Fig. 5) at different times after voltage application $(200 \mathrm{kV}$ followed by inversion) for different thermal conditions. For b), the cable is initially at $30^{\circ} \mathrm{C}$ and a current of $1 \mathrm{kA}$ is injected at the same time as the voltage is applied. Vertical lines indicate the boundaries of the insulators. The curves in black correspond to the set to $0 \mathrm{~V}$ after $24 \mathrm{~h}$ at $+200 \mathrm{kV}$. 


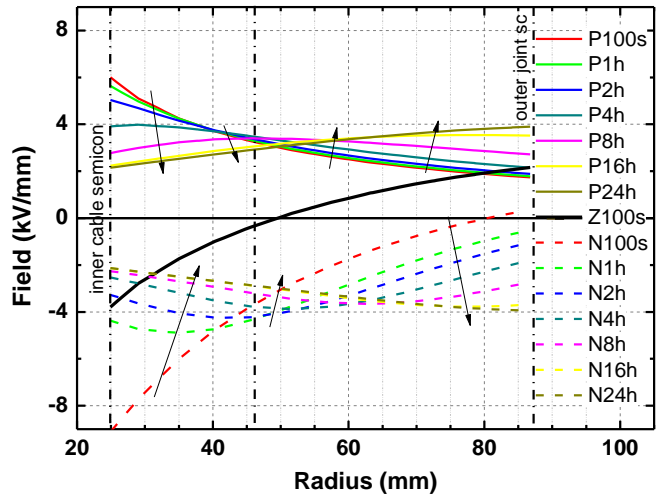

a) XLPE/XLPE T-gradient

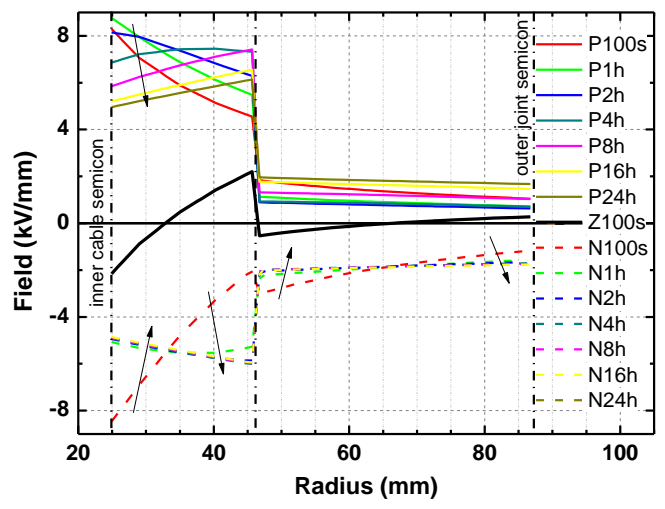

b) XLPE/SiR T-gradient

Fig. 4. Radial field distribution at different times after voltage application for XLPE/XLPE joint and XLPE/SiR joint under thermal gradient. Same conventions as in Fig. 3.

The situation for the XLPE/SiR combination (Fig. 4b), is substantially different. Here, the conductivity is higher in the SiR and therefore the field is higher in the XLPE part. The field redistribution is particularly fast after polarity inversion because of the high temperature in XLPE and high conductivity in SiR.

\section{B. Tangential electric field}

Fig. 5 represents the tangential field profiles in the joint material (i.e. EPDM), near the interface between XLPE and EPDM, as a function of time under stress, for the same cases study as previously. Tangential field values are the same in XLPE near the interface since the continuity rule imposes a continuity in tangential electric field. Under isothermal conditions (Fig. 5b), it is clear that the tangential field is significantly greater on the right of the figure, corresponding to the deflector region. This can be explained by a geometry that does not include a field-grading cone, unlike the potential reference side of the joint. In fact, some designs use a deflector cone also for the central part of the joint set to HV [3]. The quasi-constant axial field on the ground side corresponds precisely to the region where the cone produces a non-radial component to the field. Over time, the tangential field tends to decrease on the ground side and to strengthen significantly on the HV side. These trends reflect the non-linear nature of the conductivity as well as the conductivity gradient due to the presence of two insulators. It is difficult to anticipate / explain given the divergence in geometry.

In thermal gradient condition (Fig. 5.c), the field increases over time on the cone side, by a factor 3 . As a result, in the first moments of the polarity reversal, the sign of the field is not reversed. On the HV side, the field variations are milder.
We can note the presence of a negative residual field that is added to the applied field after inversion, and therefore produces an over-stress. Globally, the values of tangential fields remain lower than in the case of isothermal conditions. This is not necessarily an effect of the thermal gradient but of the fact that, taking into account the average applied stresses, the conductivity values of the two insulators become closer by heating the junction. They are identical at $60{ }^{\circ} \mathrm{C}$ for a field of $4 \mathrm{kV} / \mathrm{mm}$, while at $30{ }^{\circ} \mathrm{C}$ the equivalence is obtained under a field of $15 \mathrm{kV} / \mathrm{mm}$ (Fig. 2) which is never reached here.

Using a single material, XLPE (Fig. 6a), under thermal gradient, the evolution of the field distribution is similar to the one with XLPE/EPDM in the same conditions (Fig. 5c). It means that, for the cases considered here, the temperature conditions are more important than the material nature. With the SiR joint material (Fig. 6b) having a much larger conductivity than XLPE, there is practically no field distortion on the ground side (the residual field at voltage removal is nearly zero) and the field is small compared to other cases. On the HV side, there is also a mild variation of the field with time, and hence weak residual field at grounding. Here the field reaches the highest values at about $7.5 \mathrm{kV} / \mathrm{mm}$ in steady state. The profiles are in fact similar to the ones of Fig 5.b: the common feature here is a higher conductivity in the joint material than in XLPE.

Besides conductivity differences, the temperature distribution may affect the field distribution. Fig. 7 shows that due to lower thermal conductivity in $\mathrm{SiR}$, the temperature is

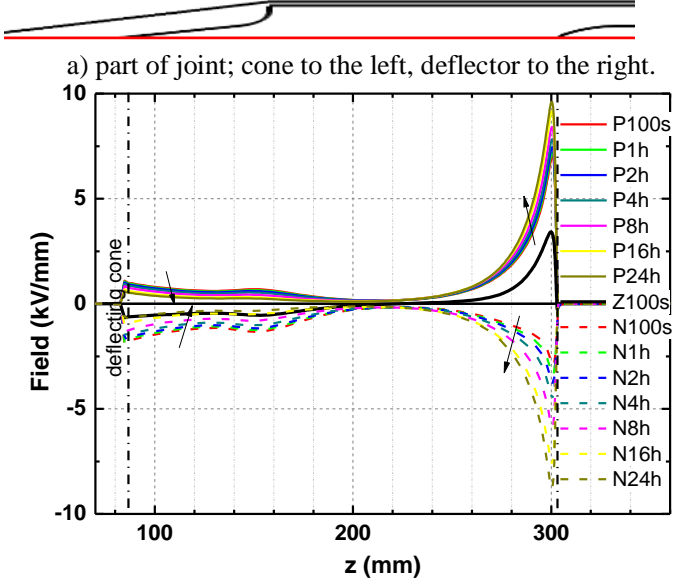

b) XLPE/EPDM Isotherm $30^{\circ} \mathrm{C}$

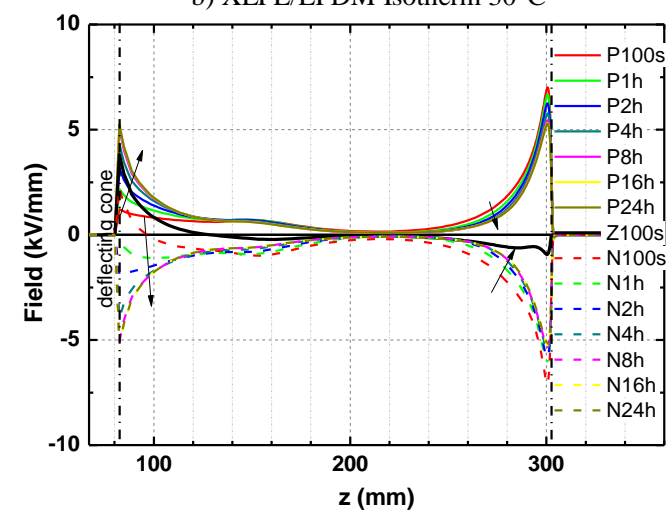

c) XLPE/EPDM T-gradient

Fig. 5. Axial field distribution at the XLPE/EPDM interface at different times after voltage application. Vertical lines define insulator boundaries. The curve in black corresponds to the reset to 0 after $24 \mathrm{~h}$ at $+200 \mathrm{kV}$. Ground on the left; HV on the right. A part of the joint is shown in a) to position the profile with respect to it. 


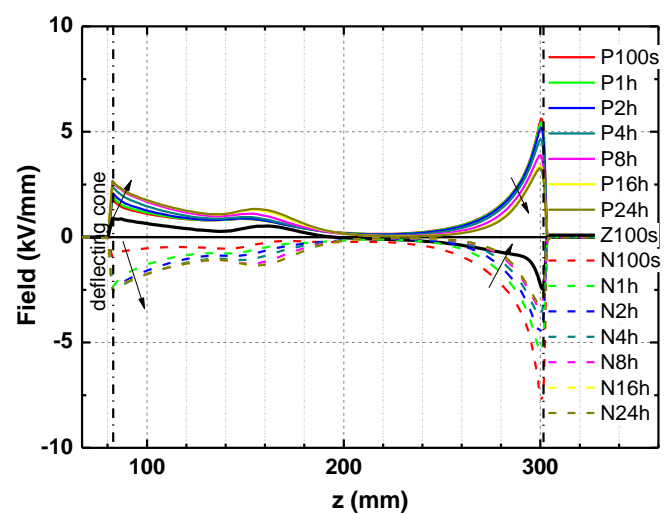

a) XLPE/XLPE T-gradient

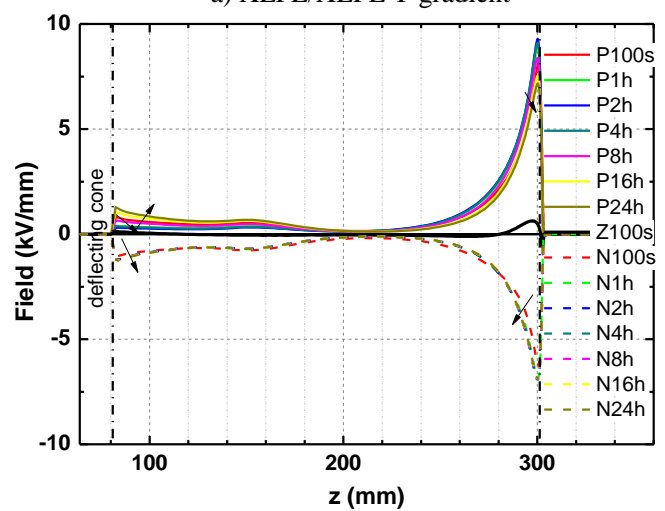

b) XLPE/SiR T-gradient

Fig. 6. Axial field distribution at the a) XLPE/XLPE and b) XLPE/SiR interface at different times after voltage application. Vertical lines define insulator boundaries. Same conventions as in Fig. 5.

significantly higher in this case. It explains why the radial field redistributes faster in XLPE in Fig. 4 than in Fig. 3 for example. Thermal gradients along the axial direction (not shown here) are milder (rise by about $10^{\circ} \mathrm{C}$ from the ground to $\mathrm{HV}$ electrode) than along the radial direction and the absolute temperature varies. A more complete investigation with isotherms at different temperatures would be necessary to identify the governing rules for the tangential field.

To obtain an equilibrated tangential field distribution along the interface, the conductivities of the two insulations should be close. However, the field is not homogeneous in the junction, neither is the temperature and we have seen in the measurements that only in particular combinations (fieldtemperature), equal values of conductivity are obtained. It is in fact difficult to have similar conductivities from materials so different as silicones or EPDM and XLPE. The use of an elastomer remains essential to apply a homogeneous pressure and match the shape of the insulated cable. This avoids surface tracking, surface discharges and the resulting failures. However, the switch from XLPE to an elastomer leads to different dielectric behaviours, whether it be the conduction processes or the field and temperature dependencies, which result therefrom. It is further complicated to produce materials having a predefined electrical conductivity.

Compared to other studies on field distributions in joints, the work presented here considers the transient conditions of field arrangement whereas very often only a direct resolution in stationary state is proposed. Multiple stress conditions can be tested. This is quite easily achievable, but it is important to stress that the collection of experimental data on conductivity,

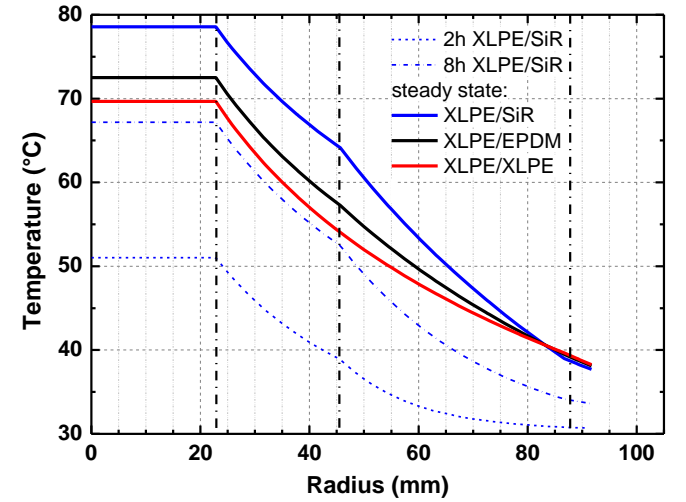

Fig. 7. Radial temperature profiles in quasi-steady state $(24 \mathrm{~h})$ for the three material couples considered and profiles during thermal transient for XLPE/SiR at $2 \mathrm{~h}$ and $8 \mathrm{~h}$.

representative of materials in operating conditions, is a major preliminary step in all these modelling and design tasks.

\section{CONCLUSION}

The field distribution in HVDC cable joints has been investigated in non-stationary electrical and thermal conditions, considering XLPE as cable insulation and different materials as joint insulation. The radial distribution of the field follows expected trends with temperature, depending on materials electrical conductivity. At the level of the high voltage semicon, it is clear that the tangential field is higher when the mismatch between the conductivity of the two insulations is larger. Under the deflecting cone, the situation is not so clear. The smallest field value and field redistribution is obtained with the joint insulation having the highest electrical conductivity. Thermal gradient effects are still to be analyzed.

\section{ACKNOWLEDGMENT}

This work is supported by CNRS International Scientific Cooperation Program (PICS) N PICS07965.

\section{REFERENCES}

[1] G. Mazzanti et al., "The insulation of HVDC extruded cable system joints. Part 1: Review of materials, design and testing procedures," IEEE Trans. Dielectr. Electr. Insul., vol. 26, pp. 964-972, 2019

[2] H. Ghorbani, M. Jeroense, C.-O. Olsson, and M. Saltzer, "HVDC cable systems-Highlighting extruded technology," IEEE Trans. Power Deliv., vol. 29, pp. 414-421, 2014

[3] H. Ye, Z. Han, Y. Luo, Q. Zhuang, T. Fechner, H. Wang, and X. Lei, "Design aspects on HVDC cable joints," Proc. 12th Int. Conf. Prop. Appl. Dielectr. Materials (ICPADM), pp. 300-304, 2018

[4] F. Mauseth and H. Haugdal, "Electric field simulations of high voltage DC extruded cable systems," IEEE Electr. Insul. Mag., vol. 33-4, pp. 16-21, 2017

[5] C. Stancu, P.V. Notingher, P. Notingher, and M. Lungulescu, "Space charge and electric field in thermally aged multilayer joints model," IEEE Trans. Dielectr. Electr. Insul., vol. 23, pp. 633-644, 2016

[6] T.T.N. Vu, G. Teyssedre, B. Vissouvanadin, S. Le Roy, and C. Laurent, "Correlating conductivity and space charge measurements in multidielectrics under various electrical and thermal stresses," IEEE Trans. Dielectr. Electr. Insul., vol. 22, pp. 117-127, 2015

[7] T.T.N. Vu, G. Teyssedre, B. Vissouvanadin, S. Le Roy, C. Laurent, M. Mammeri, and I. Denizet, "Field distribution under temperature gradient in polymeric MV-HVDC model cable: simulation and space charge measurements", Eur J. Electr. Engg., vol. 17, pp. 307-325, 2014

[8] M. A. Baferani, T. Shahsavarian, C. Li, M. Tefferi, I. Jovanovic, and Y. Cao, "Electric field tailoring in HVDC cable joints utilizing electrothermal simulation: effect of field grading materials," Proc. 2020 IEEE Electrical Insulation Conference (EIC), pp. 400-404, 2020 
